\title{
BMJ Open Serological investigation to identify risk factors for post-flood infectious diseases: a longitudinal survey among people displaced by Typhoon Morakot in Taiwan
}

Chun-Yu Lin, ${ }^{1,2}$ Tun-Chieh Chen, ${ }^{1,2}$ Chia-Yen Dai, ${ }^{3}$ Ming-Lung Yu, ${ }^{3}$ Po-Liang Lu, ${ }^{1,2}$ Jeng-Hsien Yen, ${ }^{2}$ Yen-Hsu Chen ${ }^{1,2}$

To cite: Lin C-Y, Chen T-C, Dai $\mathrm{C}-\mathrm{Y}$, et al. Serological investigation to identify risk factors for post-flood infectious diseases: a longitudinal survey among people displaced by Typhoon Morakot in Taiwan. BMJ Open 2015;5:e007008. doi:10.1136/bmjopen-2014007008

- Prepublication history for this paper is available online. To view these files please visit the journal online (http://dx.doi.org/10.1136/ bmjopen-2014-007008).

Received 24 October 2014 Revised 17 April 2015 Accepted 21 April 2015

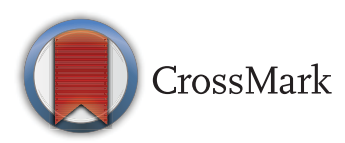

For numbered affiliations see end of article.

Correspondence to Dr Yen-Hsu Chen; d810070@cc.kmu.edu.tw

\section{ABSTRACT}

Objectives: After Typhoon Morakot struck Taiwan in 2009, thousands of Taiwanese citizens were displaced to shelters for several weeks. Others were placed in urban communities where they had family members. This study aimed to investigate serological status in both groups and identify risk factors associated with seroconversion of infectious diseases.

Design: A longitudinal survey.

Setting: All experimental and clinical investigations were performed in a tertiary teaching hospital.

Participants: A total of 288 displaced persons (96 males and 192 females) were recruited and complete follow-up data through two rounds of sampling were collected. The average age was 58.42 years (range $31-87$ years).

Interventions: First, serum specimens were collected between December 2009 and January 2010, 4-5 months after the typhoon. The second round of specimen collection was carried out after 6 months.

Primary and secondary outcome measures: The primary outcome measured was serological status of vaccine-preventable droplet-borne infectious diseases (ie, measles, mumps, rubella) and water-borne diseases (ie, amoebiasis and leptospirosis). The secondary outcome was identification of risk factors for seroconversion using univariate and multivariate analyses.

Results: Complete data were available for all 288 displaced persons (114 from the shelter group; 174 from the community group). Seroconversion of Entamoeba histolytica was observed in 128 (44.4\%) participants, with a significantly higher rate in the shelter group than in the community group ( $56.1 \%$ vs $36.8 \% ; p=0.001)$. There were 10 cases of rubella seroconversion. After adjusting for medical history, hypertension and hyperlipidaemia, shelter stay was associated with higher risk for seroconversion (OR=2.055, 95\% Cl 1.251 to $3.374 ; p=0.004$ ). Amoebiasis was more evident in the shelter group, although the manifestations were mild.

Conclusions: Our results suggested that (1) a clean water supply is essential postdisaster, especially in

\section{Strengths and limitations of this study}

- Shelter stay was associated with higher risk for seroconversion of Entamoeba histolytica.

- Amoebiasis was more evident among displaced persons staying in shelters.

- Data from two rounds of examinations were available for all 288 displaced persons.

- No direct examination of drinking water in the shelters was carried out.

crowded shelters, and (2) vaccination programmes should be extended to populations at higher risk for post-disaster displacement or to those with weakened immune status.

\section{INTRODUCTION}

Climate change, resulting from an imbalance between radiation entering and exiting the atmosphere, is thought to alter the hydrological cycle. ${ }^{1}$ In the past few decades, climate change and global warming have been suggested as the triggers for increased severity of cyclones, flooding ${ }^{2}$ and major hurricane-related damage, even in temperate regions. ${ }^{3}$ Flooding, which is the most common type of disaster globally, ${ }^{4}$ has significantly impacted places such as Hunan, China, where river flooding has caused an increase in mortality rates as well as potential years of lost life. ${ }^{5}$

Natural disasters such as typhoons, cyclones, earthquakes, tsunamis or flooding are also associated with an increased incidence of vector-borne and water-borne infectious diseases. ${ }^{167}$ Indeed, a number of reports have suggested that large-scale cyclones with extensive flooding impose a burden on the public 
health system ${ }^{8}$ due to outbreaks of infectious diseases such as cholera, typhoid fever, acute hepatitis A, leptospirosis, melioidosis, measles, dengue fever, malaria and amoebiasis. ${ }^{9-13}$ An important contributory factor for such disease outbreaks may be the displacement of large numbers of people from their homes into over-crowded shelters where supplies may be limited. ${ }^{9}$ The availability and accessibility of medical services after such natural disasters is also a major concern. ${ }^{14}$ Epidemiological studies have reported that the increased incidence of infectious diseases after such disasters is associated with environmental changes, crowded shelter conditions and an inadequate or dirty water supply. ${ }^{9-12}$ Risk behaviours linked to sexually transmitted diseases also may increase after a disaster as a result of the unaccompanied status of primary sex partners. ${ }^{15}$

Typhoon Morakot struck southern Taiwan between 7 and 9 August 2009, with massive rainfall $(>1000 \mathrm{~mm}$ ) and flooding, resulting in 673 deaths and property losses of more than 19 billion New Taiwan Dollars. In contrast to tsunamis, where flooding occurs along coastal areas, the major rainfall and flooding during Typhoon Morakot occurred along coastal areas as well as inland areas. Southern Taiwan had the most severe damage in mountainous and coastal areas. ${ }^{16}$ Thousands of Taiwanese citizens were displaced from their original residences in coastal, plains and mountainous areas, and moved to shelters or to urban communities. This movement made the collection and accuracy of medical records unreliable. Owing to these challenges, no longitudinal population-based surveys were conducted either during or after Typhoon Morakot to examine the occurrence of infectious diseases among displaced people. It is also not clear which post-disaster shelter policies should be examined with caution when drafting guidelines for prevention of infectious diseases.

In order for government agencies to prepare more effectively for post-disaster management, it is important: (1) to understand differences between disaster-displaced persons staying in shelters and those remaining in the community, and (2) to collect adequate and accurate population-based serological epidemiological evidence of infectious diseases after such disasters.

In this longitudinal study, we performed serological testing to track communicable diseases in two groups of people displaced from their homes: those who were moved to shelters, and those who remained in the community. The major aims of this study were: (1) to investigate the serological status of vaccine-preventable droplet-borne and water-borne infectious diseases in displaced persons staying in shelters, and those in the community, and (2) to identify risk factors associated with seroconversion of infectious diseases.

\section{MATERIALS AND METHODS}

This longitudinal epidemiological survey of 288 adult flood-displaced persons was conducted between December 2009 and July 2010, during the post-flood period 4-11 months after Typhoon Morakot in Taiwan. People living in the mountainous areas who were moved for longer than 2 weeks into shelters equipped with beds and a water supply were categorised as the shelter group. Those who had lived in a shelter for less than 2 weeks were excluded from further analysis. In contrast, storm-displaced persons who did not move into shelters, but went to live with their families in urban areas, were categorised as the community group. All 288 cases were from the Kaohsiung County. Hepatitis A vaccination was provided to those people who lived in the mountainous areas for several years before this typhoon. ${ }^{17}$ The Institutional Review Board of Kaohsiung Medical University Hospital reviewed and approved the study protocol, and all participants provided written informed consent. People younger than 20 years old were excluded from the study.

\section{Study design}

We sampled the first serum specimens between December 2009 and January 2010, 4-5 months after the typhoon. We performed second-round testing after 6 months. At the first and second sampling, each participant was asked to complete a structured questionnaire, either individually or with the help of trained staff during a face-to-face interview. The first questionnaire (for first sampling) included epidemiological data, underlying diseases and severity of trauma during the typhoon (family member's death or major trauma). The second questionnaire (for second sampling) included duration of shelter stay before returning to one's original residence.

\section{First-round sampling}

The first-round specimens were analysed for biochemistry data and nutritional status. Serological tests included IgG levels for vaccine-preventable diseases (measles, mumps and rubella, which all require mandatory notification), E. histolytica serological titres (IgG using IHA (indirect haemagglutination)) and $\operatorname{IgM} / \operatorname{IgG}$ for leptospirosis. We also measured IgG levels of herpes simplex virus (HSV)-1, HSV-2 and Venereal Disease Research Laboratory, for syphilis. Amoebiasis (IHA), HSV-1 and HSV-2 tests were performed by the College of American Pathologists (CAP) Accreditation Programmes Laboratory. All other tests were performed in our own laboratory, which is a Biosafety level-2 (BSL-2) certified lab.

Table 1 lists the details of the serological test kits used in the present study. Patients with positive syphilis screening results were contacted between first-round and second-round specimen collection, their serum was reanalysed and they were provided adequate treatment. No scheduled vaccination programme was provided to the shelter group or to the community group between the two samplings, except for vaccination for the 2009 pandemic H1N1 influenza strain. ${ }^{18}$ 
Table 1 Serological test kits used in the present study

\begin{tabular}{|c|c|c|c|c|}
\hline Disease & Products & Manufacturer & City & Country \\
\hline Measles & Measles virus IgG-ELISA & NovaLisa & Dietzenbach & Germany \\
\hline Mumps & Mumps virus IgG-ELISA & NovaLisa & Dietzenbach & Germany \\
\hline Rubella & Rubella virus IgG-ELISA & NovaLisa & Dietzenbach & Germany \\
\hline Amoebiasis (IHA) & Cellognost-Amoebiasis & Behring Diagnostics & Marburg & Germany \\
\hline Leptospirosis & OnSite Leptospira IgG/lgM Combo Rapid Test & CTK Biotech, Inc & San Diego, CA & USA \\
\hline HSV-1 & Anti-HSV-1 ELISA (IgG) & Euroimmun & Lübeck & Germany \\
\hline HSV-2 & Anti-HSV-2 ELISA (IgG) & Euroimmun & Lübeck & Germany \\
\hline VDRL of syphilis & Syphilis RPR Test & Human & Wiesbaden & Germany \\
\hline
\end{tabular}

\section{Second-round sampling}

Six months after the first sampling, a second-round serum sampling was conducted to evaluate for measles, mumps, rubella and E. histolytica, using the same methods. If a participant had negative results for measles, mumps and/or rubella in the first round, and positive results in the second, we defined this as an IgG seroconversion. (If a participant had positive results for measles, mumps and/or rubella in the first-round already, he or she did not receive recheck of measles, mumps and/or rubella IgG in the second-round). The cut-off value of positive results of the IHA test for amoebiasis was previously established as $\geq 1: 128{ }^{19}{ }^{20}$ However, there is evidence that this cut-off value may miss some cases with parasitologically positive amoebiasis. ${ }^{21}{ }^{22}$ Therefore, with two blood samples collected at an interval of at least 16 weeks, we defined IgG seroconversion for amoebiasis as $\geq 1: 64$ at the second sampling as well as a fourfold titre increase when compared to first sampling results, which indicates recent infection. ${ }^{23}$

\section{Follow-up telephone interview}

Telephone interviews were conducted for all displaced persons with IHA seroconversion within 1 month after the second sampling. The structured questionnaire that was used mainly inquired about gastrointestinal symptoms and signs of amoebiasis, including diarrhoea, abdominal pain and dysentery.

\section{Statistical analysis}

Data were summarised as n (\%) for categorical variables, mean \pm SD for continuous variables and median (IQR: Q1, Q3) for continuous variables with non-normal distribution. Between-group differences in categorical data were compared by Pearson $\chi^{2}$ test or Fisher's exact test if case numbers were less than five. Between-group differences in continuous data were compared by two-sample $\mathrm{t}$ test and by Mann-Whitney $\mathrm{U}$ test if data were without normal distribution. Associations between seroconversion among shelter stay, participants' demographics, medical history and laboratory data were further identified. Variables significantly associated with seroconversion were placed into univariate and multivariate logistic regression analysis. Results were presented as ORs and corresponding $95 \%$ CIs of OR (95\% CI) and $p$ values. All statistical assessments were two-tailed and $\mathrm{p}<0.05$ represented statistical significance. All analyses were conducted using SPSS statistical software V.18.0 (SPSS Inc, Chicago, Illinois, USA).

\section{RESULTS}

\section{Demographic characteristics and laboratory data}

A total of 288 participants (96 males/192 females) with complete follow-up data through two rounds of sampling were enrolled into evaluation. The average age was 58.42 years $(\mathrm{SD}=12.73)$ with a range of 31 to 87 years. Table 2 summarises the demographics, medical history and laboratory data of participants in the shelter group, and those in the community group. There was no significant difference in the distribution of demographics and medical histories between the two groups (all p $>0.05$ ). Although there was a difference in age between the shelter and community groups, this difference was of borderline significance (median (IQR): $55(48,66)$ vs $57(50,70), \mathrm{p}=0.049)$. The second round of testing showed that participants placed in shelters had significantly higher levels of serum glutamic pyruvate transaminase (GPT values; serum GPT $>40 \mathrm{IU} / \mathrm{L}$ ) as well as significantly lower total cholesterol values than those in the community (serum GPT: $28.9 \%$ vs $13.2 \%, p=0.001$; total cholesterol: $188.65 \pm 38.33 \mathrm{mg} / \mathrm{dL} \quad$ vs 199.15 $\pm 42.40 \mathrm{mg} / \mathrm{dL}, \mathrm{p}=0.034$; table 2 ). Comparison of firstround and second-round data showed that participants in shelters had significantly higher levels of serum GPT, but significantly lower levels of serum albumin and total cholesterol than participants in the community (all $\mathrm{p}<0.05)$.

\section{First-round serology results}

Table 3 summarises the first round of serology tests. First round testing after the typhoon showed that participants in shelters had a significantly higher rate of mumps, but a significantly lower rate of HSV-2, compared to the community group (mumps: $81.6 \%$ vs $69.5 \%, \mathrm{p}=0.022$; HSV-2: $27.2 \%$ vs $40.2 \%$, $\mathrm{p}=0.023$ ). All 288 participants in the first round examination were subjected to a second round of testing after 6 months. There were no 
Table 2 Participants' demographics, medical history and laboratory data by group $(\mathrm{N}=288)$

\begin{tabular}{|c|c|c|c|c|}
\hline Variables & $\begin{array}{l}\text { Total } \\
(\mathrm{n}=288)\end{array}$ & $\begin{array}{l}\text { Shelter group } \\
(\mathrm{n}=114)\end{array}$ & $\begin{array}{l}\text { Community group } \\
(\mathrm{n}=174)\end{array}$ & p Value \\
\hline \multicolumn{5}{|l|}{ Demographics } \\
\hline Gender, male (\%) & 96 (33.3) & $37(32.5)$ & 59 (33.9) & 0.798 \\
\hline Age $\geq 65$ years, $n(\%)$ & $94(32.6)$ & $30(26.3)$ & $64(36.8)$ & 0.064 \\
\hline BMI & $28.20 \pm 4.92$ & $28.60 \pm 4.67$ & $27.94 \pm 5.08$ & 0.268 \\
\hline Ratio of waist and hip & $0.90 \pm 0.07$ & $0.89 \pm 0.07$ & $0.90 \pm 0.07$ & 0.266 \\
\hline Education & & & & 0.913 \\
\hline Junior high school or lower & $159(55.2 \%)$ & $64(56.1 \%)$ & $95(54.6 \%)$ & \\
\hline High school and college & $54(18.8 \%)$ & $20(17.5 \%)$ & $34(19.5 \%)$ & \\
\hline Without formal education and unknown & $75(26.0 \%)$ & $30(26.3 \%)$ & $45(25.9 \%)$ & \\
\hline Singleף, n (\%) & $121(42.0)$ & $46(40.4)$ & $75(43.1)$ & 0.643 \\
\hline Family with major trauma & $10(3.5)$ & $6(5.3)$ & $4(2.3)$ & 0.201 \\
\hline \multicolumn{5}{|l|}{ Medical history } \\
\hline Hypertension & $127(46.2)$ & $53(47.3)$ & $74(45.4)$ & 0.753 \\
\hline Diabetes mellitus & $45(16.4)$ & $20(17.9)$ & $25(15.3)$ & 0.579 \\
\hline Hyperlipidaemia & $177(61.5)$ & $20(17.9)$ & $111(63.8)$ & 0.315 \\
\hline Hyperuricaemia & $91(31.6)$ & $33(28.9)$ & $58(33.3)$ & 0.434 \\
\hline Ischaemic heart disease & $10(3.6)$ & $5(4.5)$ & $5(3.1)$ & 0.543 \\
\hline Gouty arthritis & $35(12.7)$ & $19(17.0)$ & $16(9.8)$ & 0.081 \\
\hline Cerebrovascular disease & $6(2.2)$ & $1(0.9)$ & $5(3.1)$ & 0.406 \\
\hline \multicolumn{5}{|l|}{ Laboratory data } \\
\hline \multicolumn{5}{|l|}{ After typhoon (first round) } \\
\hline SERUM GPT > $40 \mathrm{IU} / \mathrm{L}$ & $49(17.0)$ & $23(20.2)$ & $26(14.9)$ & 0.248 \\
\hline Creatinine $>1.5 \mathrm{mg} / \mathrm{dL}$ & $22(7.6)$ & $8(7.0)$ & $14(8.0)$ & 0.748 \\
\hline Serum albumin, $\mathrm{mg} / \mathrm{dL}$ & $4.40(4.30,4.60)$ & $4.40(4.30,4.60)$ & $4.40(4.20,4.60)$ & 0.227 \\
\hline Total cholesterol, mg/dL & $203.98 \pm 46.34$ & $197.85 \pm 37.00$ & $208.00 \pm 51.26$ & 0.084 \\
\hline Triglyceride, mg/dL & $150(92,233.25)$ & $142(89.75,219.25)$ & $155.50(92.00,242.75)$ & 0.111 \\
\hline \multicolumn{5}{|l|}{ Follow-up (second round) } \\
\hline SERUM GPT>40 IU/L & $56(19.4)$ & 33 (28.9)‡ & $23(13.2)$ & $0.001^{*}$ \\
\hline Creatinine $>1.5 \mathrm{mg} / \mathrm{dL}$ & $20(6.9)$ & $6(5.3)$ & $14(8.0)$ & 0.364 \\
\hline Serum albumin, $\mathrm{mg} / \mathrm{dL}$ & $4.30(4.20,4.50) \dagger$ & $4.30(4.20,4.50) \ddagger$ & $4.30(4.18,4.50) \S$ & 0.447 \\
\hline Total cholesterol, mg/dL & $194.99 \pm 41.09 \dagger$ & $188.65 \pm 38.33 \ddagger$ & $199.15 \pm 42.40 \S$ & $0.034^{*}$ \\
\hline Triglyceride, $\mathrm{mg} / \mathrm{dL}$ & $150(102,257.50) \dagger$ & $142.50(98.25,208.75)$ & $156.50(102,275) \S$ & 0.240 \\
\hline
\end{tabular}

Data are summarised as $\mathrm{n}(\%)$ for categorical variables, mean \pm SD for continuous variables and median (IQR: Q1, Q3) for continuous variables without normal distribution.

Differences between shelter and community groups in categorical data were compared using Pearson $\chi^{2}$ test or Fisher's exact test if there were any cases numbering less than five; for continuous data, differences between shelter group and community group were compared using two-sample t test, and Mann-Whitney $\mathrm{U}$ test, in data without normal distribution.

${ }^{*} \mathrm{p}<0.05$, indicates significant differences between shelter and community groups.

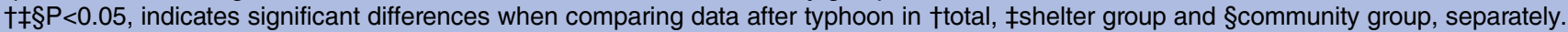
qIncluding divorced or unmarried participants, or widows or widowers.

$\mathrm{BMI}$, body mass index.

significant differences in the incidence of vaccinepreventable diseases or in water-borne diseases between participants in shelters and in community (all p>0.05). There was one case of measles seroconversion, 3 cases of mumps seroconversion and 10 cases of rubella seroconversion, in all. Of the 288 participants, 128 participants $(44.4 \%)$ showed amoebiasis seroconversion by the IHA test. The rate of amoebiasis seroconversion was higher among participants who had stayed in shelters 2 weeks or more compared to those who remained in the community $(56.1 \%$ vs $36.8 \%$; $\mathrm{p}=0.001$; table 3 ).

Associations between amoebiasis seroconversion and shelter stay, participants' demographics, medical history and laboratory data, are summarised in table 4 . Amoebiasis seroconversion was significantly associated with shelter stay and medical history, including hypertension and hyperlipidaemia (all $\mathrm{p}$ values $<0.05$; table 4 ). The length of stay in the shelter was positively and significantly associated with the rate of seroconversion (figure 1).

Table 5 represents the results of binary logistic regression analysis. Variables that were significantly associated with amoebiasis seroconversion (table 4) were placed into univariate and multivariate logistic regression analysis. Univariate analysis showed that shelter stay and hypertension were significantly associated with amoebiasis seroconversion. Paticipants with hyperlipidaemia may be at lower risk for seroconversion (all $\mathrm{p}<0.05$ ). After adjusting for medical history, hypertension and hyperlipidaemia, multivariate logistic regression analysis showed that participants who stayed in shelters had a higher 
Table 3 Positive results after the typhoon and during follow-up ( $N=288)$

\begin{tabular}{|c|c|c|c|c|}
\hline Variables & Total $(n=288)$ & $\begin{array}{l}\text { Shelter } \\
\text { group }(n=114)\end{array}$ & $\begin{array}{l}\text { Community } \\
\text { group }(n=174)\end{array}$ & p Value \\
\hline \multicolumn{5}{|l|}{ After typhoon (first round) } \\
\hline \multicolumn{5}{|l|}{ Vaccine-preventable diseases } \\
\hline Measles & $261(90.6)$ & $102(89.5)$ & $159(91.4)$ & 0.587 \\
\hline Mumps & $214(74.3)$ & $93(81.6)$ & $121(69.5)$ & $0.022^{*}$ \\
\hline Rubella & 230 (79.9) & 91 (79.9) & 139 (79.9) & 0.990 \\
\hline \multicolumn{5}{|l|}{ Water-borne diseases } \\
\hline Amoebiasis test $<1: 16$ & 89 (30.9) & $41(36.0)$ & $48(27.6)$ & 0.132 \\
\hline Leptospirosis & $2(2(0.7)$ & $0(0)$ & $2(1.1)$ & NA \\
\hline \multicolumn{5}{|l|}{ Miscellaneous } \\
\hline HSV-1 & $245(85.1)$ & $96(84.2)$ & $149(85.6)$ & 0.741 \\
\hline HSV-2 & $101(35.1)$ & $31(27.2)$ & $70(40.2)$ & $0.023^{*}$ \\
\hline VDRL for syphilis & $2(0.7)$ & $1(0.9)$ & $1(0.6)$ & 1.000 \\
\hline \multicolumn{5}{|c|}{ Follow-up with seroconversion in second round ( $n$ for negative in first round) $\dagger$} \\
\hline Measles seroconversion $(n=27)$ & $1(3.7)$ & $1(8.3)$ & $0(0)$ & NA \\
\hline Mumps seroconversion $(n=74)$ & $3(4.1)$ & $2(9.5)$ & $1(1.9)$ & 0.192 \\
\hline Rubella seroconversion $(n=58)$ & $10(17.2)$ & $5(21.7)$ & $5(14.3)$ & 0.496 \\
\hline \multicolumn{5}{|l|}{ Water-borne diseases } \\
\hline Amoebiasis test $<1: 16$ & $21(23.6)$ & $9(22.0)$ & $12(25.0)$ & 0.806 \\
\hline Leptospirosis $(n=286)$ & $0(0)$ & $0(0)$ & $0(0)$ & NA \\
\hline \multicolumn{5}{|l|}{ Miscellaneous } \\
\hline HSV-1 $(n=43)$ & $6(13.9)$ & $3(16.7)$ & $3(12)$ & 0.683 \\
\hline HSV-2 (n=187) & $3(1.6)$ & $2(2.4)$ & $1(1.0)$ & 0.585 \\
\hline VDRL for syphilis $(n=286)$ & $0(0)$ & $0(0)$ & $0(0)$ & NA \\
\hline \multicolumn{4}{|l|}{ With amoebiasis (IHA) seroconversion } & $0.001^{*}$ \\
\hline Yes & $128(44.4)$ & $64(56.1)$ & $64(36.8)$ & \\
\hline No & $160(55.6)$ & $50(43.9)$ & $110(63.2)$ & \\
\hline \multicolumn{5}{|c|}{$\begin{array}{l}\text { Data are presented as } n(\%) \text { by accommodations (shelter vs community), and compared using Pearson } \chi^{2} \text { test or Fisher's exact test if any } \\
\text { cells number less than five. } \\
{ }^{*} p<0.05 \text { indicates significant difference between shelter and community groups. } \\
\text { †Second round testing was carried out for those participants who had negative results after the first round of testing. } \\
\text { HSV, herpes simplex virus; VDRL, Venereal Disease Research Laboratory. }\end{array}$} \\
\hline
\end{tabular}

risk for seroconversion than those in community. $(\mathrm{OR}=2.055,95 \%$ CI 1.251 to $3.374 ; \mathrm{p}=0.004$; table 5$)$.

\section{Clinical manifestation of amoebiasis seroconversion}

We retrospectively interviewed 60 seroconverted participants in order to evaluate disease severity. Only $3(5 \%)$ of these patients reported acute diarrhoea (less than 14 days) without dysentery.

\section{DISCUSSION}

This longitudinal study, which was conducted after Typhoon Morakot and the accompanying flooding, showed that E. histolytica seroconversion rates were higher in persons displaced to shelters compared to those remaining in the community, although disease manifestation was mild or asymptomatic. There were a few instances of vaccine-preventable diseases such as measles, mumps and rubella, among displaced participants in the shelter group as well as among those in the community group. These diseases likely occurred in unvaccinated participants or in those with weakened immune systems. The risk of amoebiasis seroconversion was higher in participants displaced to shelters who had hypertension and lower in participants with hyperlipidaemia. However, after adjusting for medical history, hypertension and hyperlipidaemia, multivariate logistic regression analysis showed that participants who stayed in shelters had a significantly higher risk for amoebiasis seroconversion than those in the community.

Recent data suggested a relationship between massive precipitation and climate-related diseases in Taiwan (ie, enterovirus infection, Japanese encephalitis, scrub typhus, dengue fever and, to some extent, meliodosis and leptospirosis). ${ }^{24}$ However, the relationship between parasitic diseases and extreme rainfall remains unclear. Although Taiwan is considered a low-endemic area for amoebiasis, ${ }^{20}$ and notification of cases to the Center for Disease Control (CDC) is mandatory, our present study showed that amoebiasis is not uncommon in Taiwan. The annual number of cases reported to the CDC in Taiwan ranged from only 146 to 264 between 2007 and $2011,{ }^{25}$ and studies suggested that there are many asymptomatic infections. $^{26}$

Unlike outbreak reports, this longitudinal, paired serological epidemiological investigation relied on evidence 
Table 4 Associations between accommodations, participants' demographics, medical history, laboratory data and seroconversion $(\mathrm{N}=288)$

\begin{tabular}{|c|c|c|c|}
\hline Variables & $\begin{array}{l}\text { Seroconversion } \\
(n=128)\end{array}$ & $\begin{array}{l}\text { Without seroconversion } \\
(n=160)\end{array}$ & p Value \\
\hline Accommodations & & & $0.001^{*}$ \\
\hline Community & $64(36.8)$ & $110(63.2)$ & \\
\hline Shelter & $64(56.1)$ & $50(43.9)$ & \\
\hline \multicolumn{4}{|l|}{ Demographics } \\
\hline Gender & & & 0.933 \\
\hline Males & $43(44.8)$ & $53(55.2)$ & \\
\hline Females & $85(44.3)$ & $107(55.7)$ & \\
\hline Age $\geq 65$ years & & & 0.955 \\
\hline No & $86(44.3)$ & $108(55.7)$ & \\
\hline Yes & $42(44.7)$ & $52(55.3)$ & \\
\hline Age, yrs & $59.02 \pm 12.33$ & $57.94 \pm 13.05$ & 0.475 \\
\hline $\mathrm{BMI}, \mathrm{kg} / \mathrm{m}^{2}$ & $28.29 \pm 4.81$ & $28.13 \pm 5.02$ & 0.788 \\
\hline Ratio of waist and hip & $0.90 \pm 0.07$ & $0.89 \pm 0.07$ & 0.491 \\
\hline Education & & & 0.919 \\
\hline Junior high school or lower & $69(43.4)$ & $90(56.6)$ & \\
\hline High school and college & 25 (46.3) & $29(53.7)$ & \\
\hline Without formal education and unknown & $34(45.3)$ & $41(54.7)$ & \\
\hline Singlet, n (\%) & & & 0.364 \\
\hline No & $78(46.7)$ & 89 (53.3) & \\
\hline Yes & $50(41.3)$ & $71(58.7)$ & \\
\hline Family with major trauma & & & 0.348 \\
\hline No & $122(43.9)$ & $156(56.1)$ & \\
\hline Yes & $6(60.0)$ & $4(40.0)$ & \\
\hline \multicolumn{4}{|l|}{ Medical history } \\
\hline Hypertension & $66(52.0)$ & $61(48.0)$ & $0.044^{*}$ \\
\hline Diabetes mellitus & $24(53.3)$ & $21(46.7)$ & 0.246 \\
\hline Hyperlipidaemia & $70(39.5)$ & $107(60.5)$ & $0.035^{\star}$ \\
\hline Hyperuricaemia & $44(48.4)$ & 47 (51.6) & 0.436 \\
\hline Ischaemic heart disease & $3(30.0)$ & $7(70.0)$ & 0.246 \\
\hline Gouty arthritis & $16(45.7)$ & $19(54.3)$ & 0.974 \\
\hline Cerebrovascular disease & $3(50.0)$ & $3(50.0)$ & 1.000 \\
\hline \multicolumn{4}{|l|}{ Laboratory data } \\
\hline \multicolumn{4}{|l|}{ Pretest } \\
\hline Serum GPT >40 IU/L & $23(46.9)$ & $26(53.1)$ & 0.700 \\
\hline Creatinine $>1.5 \mathrm{mg} / \mathrm{dL}$ & $7(31.8)$ & 15 (68.2) & 0.215 \\
\hline Serum albumin, $\mathrm{mg} / \mathrm{dL}$ & $4.40(4.30,4.60)$ & $4.40(4.30,4.60)$ & 0.302 \\
\hline Total cholesterol, mg/dL & $200.16 \pm 36.32$ & $207.04 \pm 52.93$ & 0.194 \\
\hline Triglyceride, $\mathrm{mg} / \mathrm{dL}$ & $148.50(84.00,202.50)$ & $160.50(95.30,261.00)$ & 0.167 \\
\hline \multicolumn{4}{|l|}{ Follow-up } \\
\hline Serum GPT >40 IU/L & $29(51.8)$ & $27(48.2)$ & 0.218 \\
\hline Creatinine $>1.5 \mathrm{mg} / \mathrm{dL}$ & $7(35.0)$ & $13(65.0)$ & 0.378 \\
\hline Serum albumin, $\mathrm{mg} / \mathrm{dL}$ & $4.30(4.10,4.40)$ & $4.30(4.20,4.50)$ & 0.087 \\
\hline Total cholesterol, $\mathrm{mg} / \mathrm{dL}$ & $191.74 \pm 39.90$ & $197.59 \pm 41.96$ & 0.230 \\
\hline Triglyceride, $\mathrm{mg} / \mathrm{dL}$ & $193.00(162.00,214.75)$ & $156.50(106.00,261.00)$ & 0.248 \\
\hline
\end{tabular}

Data are summarised as $n(\%)$ for categorical variables, mean $\pm S D$ for continuous variables, and median (IQR: Q1, Q3) for continuous variables without normal distribution.

Differences between participants with and without seroconversion in categorical data were compared using Pearson $\chi^{2}$ test or Fisher's exact test if there were any cells numbering less than five; for continuous data, differences between participants with and without seroconversion were compared using two-sample $t$ test and Mann-Whitney $\mathrm{U}$ test in data without normal distribution.

${ }^{*} p<0.05$, indicates significant differences between participants with and without seroconversion.

tIncluding divorced or unmarried participants, or widows or widowers.

BMI, body mass index.

of seroconversion to evaluate the incidence of infectious diseases among different populations of disasterdisplaced persons. We found that prolonged shelter stay was associated with higher E. histolytica antibody seroconversion rates after Typhoon Morakot, even though those who showed seroconversion presented only mild symptoms or were asymptomatic. Our postdisaster serological data were consistent with a study of 


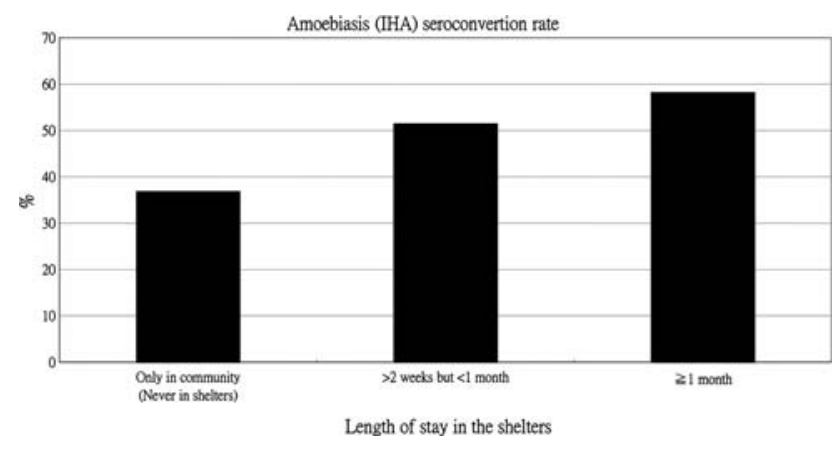

Figure 1 Amoebiasis indirect haemagglutination (IHA) seroconversion rate in groups with different lengths of stay in the shelters.

clinical laboratory methods of E. histolytica detection, which noted the asymptomatic nature of amoebiasis. ${ }^{23}$ Our data strongly suggested that contaminated water supply in crowded shelters could play a major role in amoebiasis outbreaks seen after natural disasters. We suggest that a clean drinking water supply is crucial during post-disaster care and management, especially for displaced persons admitted to shelters. The presence of $E$. histolytica seroconversion among disaster-displaced people living in the community may be due to disasterdamaged public drinking water systems whereby some people living with their families in urban areas may also become infected.

Although an outbreak of leptospirosis was previously reported in Pingtung County (a non-mountainous area) after Typhoon Morakot, and melioidosis was also confirmed in areas of heavy precipitation after the typhoon, ${ }^{12}$ there were no reports of leptospirosis outbreaks made to the CDC from the mountainous areas during our study period. This discrepancy suggested that rainfall levels and cumulative flooding may have a greater impact on leptospirosis and melioidosis outbreaks compared to typhoon strength.

Our data showed that a greater percentage of displaced persons admitted to shelters had family members who suffered a major trauma resulting in serious injury or death. On the other hand, the higher percentage of older displaced persons in the community group may be due to the fact that family members who originally resided in urban areas before Typhoon Morakot (not included in our cohort) were more likely to provide shelter to their elderly relatives. Different environmental circumstances as well as the different vaccine coverage rates among various age groups may explain the different seropositivity rates for mumps between younger adults in the two groups. However, among people aged $\geq 50$ years in both groups, the baseline seropositivity rates for mumps were not different $(74 \%$ in the shelter group vs $67.9 \%$ in the community group; $\mathrm{p}=0.150$; data not shown).

Our present data showed some cases of seroconversion for vaccine-preventable diseases such as measles, mumps and, especially, rubella, among displaced persons during the study period. Although there were no significant differences in the seroconversion rates for these three diseases between the shelter and community groups, evidence of seroconversion among displaced persons suggested that there was a risk of outbreaks under these conditions. It is important to note that vaccine coverage rates are high in Taiwan, and there were no outbreaks during our study period, unlike the concurrent measles and rubella outbreaks in camps hosting Liberian displaced persons in Côte d'Ivoire in 2004. ${ }^{27}$ However, our data suggested that there was a risk of vaccinepreventable diseases after the disaster, regardless of the type of accommodations. Outbreaks of infectious diseases such as rubella in crowded shelters after natural disasters can be effectively prevented by extending vaccination programmes to populations who have a higher risk of post-disaster displacement and who are without antibody protection.

There is currently little evidence to provide guidance on whether staying in shelters is a more advantageous post-disaster accommodation policy in terms of preventing disease transmission among large numbers of displaced people, compared to remaining in the community. To our knowledge, this is the first study investigating differences in seroconversion rates between disaster-displaced persons staying in different types of accommodations. Our present data are consistent with previous results showing that effective post-disaster management and mitigation strategies are necessary to address the needs of flood-displaced persons, and to reduce the risk of communicable diseases, ${ }^{4}{ }^{28}$ especially

Table 5 Univariate and multivariate logistic regression models analysis of seroconversion $(\mathrm{N}=288)$

\begin{tabular}{|c|c|c|c|c|}
\hline Variables† & $\begin{array}{l}\text { Univariate } \\
\text { OR }(95 \% \mathrm{Cl})\end{array}$ & p Value & $\begin{array}{l}\text { Multivariate } \\
\text { OR }(95 \% \mathrm{CI})\end{array}$ & p Value \\
\hline \multicolumn{5}{|l|}{ Shelter admission } \\
\hline Shelter versus community & 2.200 (1.359 to 3.561$)$ & $0.001^{*}$ & 2.055 (1.251 to 3.374$)$ & $0.004^{*}$ \\
\hline \multicolumn{5}{|l|}{ Medical history } \\
\hline Hypertension & 1.632 (1.011 to 2.635$)$ & $0.045^{\star}$ & 1.576 (0.964 to 2.575$)$ & 0.070 \\
\hline Hyperlipidaemia & 0.598 (0.370 to 0.965$)$ & $0.035^{\star}$ & $0.642(0.389$ to 1.060$)$ & 0.083 \\
\hline
\end{tabular}


in vulnerable groups such as younger children and older adults with weaker immune systems. ${ }^{29}$

This study has several limitations. First, only $46.9 \%$ of the participants with E. histolytica IHA seroconversion were retrospectively interviewed. Bias in participants' ability to recall clinical symptoms or signs was also a limitation. Second, we did not directly examine the drinking water in the shelters; thus, a direct causal relationship between drinking water and E. histolytica seroconversion could not be established even though the risk of seroconversion was significantly higher in the shelter group compared to the community group. Another limitation was that although we recognise the importance of covering all infectious diseases in post-crisis situations, we could only investigate diseases based on local interests in this study. Finally, the sample size for this longitudinal study was relatively small. It is important to validate our current findings with a larger sample size.

In conclusion, after Typhoon Morakot, shelter stay was associated with higher risk for seroconversion of $E$. histolytica. Although displaced persons staying in shelters had higher seroconversion rates than those remaining in the community, manifestations were mild. Our results provide useful information for the pre-emptive preparation and response to relatively predictable typhoons and flooding, and suggested that a clean water supply is essential after a disaster, especially in relatively crowded shelters. Our finding of measles, mumps and rubella seroconversion among displaced participants, strongly suggested that prevention of large outbreaks of infectious diseases following natural disasters could be prevented by extending vaccination programmes to populations at higher risk for post-disaster displacement and to those with weakened immune systems.

\section{Author affiliations}

${ }^{1}$ Division of Infectious Diseases, Department of Internal Medicine, Kaohsiung Medical University Hospital, Kaohsiung, Taiwan

${ }^{2}$ Graduate Institute of Medicine, Tropical Medicine Research Center, College of Medicine, Kaohsiung Medical University, Kaohsiung, Taiwan

${ }^{3}$ Hepatobiliary Division, Department of Internal Medicine, Kaohsiung Medical University Hospital, Kaohsiung Medical University, Kaohsiung, Taiwan

Contributors $\mathrm{C}-\mathrm{YL}, \mathrm{C}-\mathrm{YD}$ and $\mathrm{Y}-\mathrm{HC}$ conceived and designed the experiments. $\mathrm{C}-\mathrm{YL}, \mathrm{T}-\mathrm{CC}$ and P-LL analysed the data. C-YD, M-LY and J-HY contributed reagents/materials/analysis tools. C-YL, T-CC and Y-HC wrote the paper.

Funding This study was supported by a grant to $\mathrm{Y}-\mathrm{H}$ Chen and J-H Yen from the National Science Council, Taiwan (NSC 98-2321-B-037-063).

Competing interests None declared.

Patient consent Obtained.

Ethics approval The institutional review board of Kaohsiung Medical University Hospital reviewed and approved the study protocol, and all participants provided written informed consent. People younger than age 20 years were excluded from this study.

Provenance and peer review Not commissioned; externally peer reviewed.

Data sharing statement No additional data are available.

Open Access This is an Open Access article distributed in accordance with the Creative Commons Attribution Non Commercial (CC BY-NC 4.0) license, which permits others to distribute, remix, adapt, build upon this work non- commercially, and license their derivative works on different terms, provided the original work is properly cited and the use is non-commercial. See: http:// creativecommons.org/licenses/by-nc/4.0/

\section{REFERENCES}

1. Shuman EK. Global climate change and infectious diseases. N Engl J Med 2010;362:1061-3.

2. Jangi S. Facing uncertainty-dispatch from Beth Israel Medical Center, Manhattan. N Engl J Med 2012;367:2267-9.

3. Ofri D. The storm and the aftermath. $N$ Engl J Med 2012;367:2265-7.

4. Alderman K, Turner LR, Tong S. Floods and human health: a systematic review. Environ Int 2012;47:37-47.

5. Li X, Tan H, Li S, et al. Years of potential life lost in residents affected by floods in Hunan, China. Trans $R$ Soc Trop Med Hyg 2007:101:299-304.

6. McMichael AJ, Woodruff RE, Hales S. Climate change and human health: present and future risks. Lancet 2006;367:859-69.

7. Lafferty KD. The ecology of climate change and infectious diseases. Ecology 2009;90:888-900.

8. Redlener I, Reilly MJ. Lessons from Sandy-preparing health systems for future disasters. N Engl J Med 2012;367:2269-71.

9. Shultz JM, Russell J, Espinel Z. Epidemiology of tropical cyclones: the dynamics of disaster, disease, and development. Epidemiol Rev 2005;27:21-35

10. Ivers LC, Ryan ET. Infectious diseases of severe weather-related and flood-related natural disasters. Curr Opin Infect Dis 2006;19:408-14.

11. Ko WC, Cheung BM, Tang HJ, et al. Melioidosis outbreak after typhoon, southern Taiwan. Emerg Infect Dis 2007;13:896-8.

12. Su HP, Chan TC, Chang CC. Typhoon-related leptospirosis and melioidosis, Taiwan, 2009. Emerg Infect Dis 2011;17:1322-4.

13. Ahern M, Kovats RS, Wilkinson $P$, et al. Global health impacts of floods: epidemiologic evidence. Epidemiol Rev 2005;27:36-46.

14. Pape JW, Johnson WD, Jr., Fitzgerald DW. The earthquake in Haiti —dispatch from Port-au-Prince. N Engl J Med 2010;362:575-7.

15. Kissinger $P$, Liddon N, Schmidt N, et al. HIV/STI Risk behaviors among Latino migrant workers in New Orleans post-Hurricane Katrina disaster. Sex Transm Dis 2008;35:924-9.

16. Lin PC, Lin HJ, Guo HR, et al. Epidemiological characteristics of lower extremity cellulitis after a typhoon flood. PLOS ONE 2013;8:e65655.

17. Tsou TP, Liu CC, Huang JJ, et al. Change in hepatitis A epidemiology after vaccinating high risk children in Taiwan, 1995-2008. Vaccine 2011;29:2956-61.

18. Huang WT, Chuang JH, Kuo SH. Monitoring the safety of pandemic H1N1 vaccine. Lancet 2010;375:1164

19. Hung CC, Chen PJ, Hsieh SM, et al. Invasive amoebiasis: an emerging parasitic disease in patients infected with HIV in an area endemic for amoebic infection. Aids 1999;13:2421-8.

20. Hung CC, Wu PY, Chang SY, et al. Amebiasis among persons who sought voluntary counseling and testing for human immunodeficiency virus infection: a case-control study. Am J Trop Med Hyg 2011;84:65-9.

21. Hossain A, Bolbol AS, Chowdhury MN, et al. Indirect haemagglutination (IHA) test in the serodiagnosis of amoebiasis. J Hyg Epidemiol Microbiol Immunol 1989;33:91-7.

22. Rosenblatt JE, Sloan LM, Bestrom JE. Evaluation of an enzymelinked immunoassay for the detection in serum of antibodies to Entamoeba histolytica. Diagn Microbiol Infect Dis 1995;22:275-8.

23. Tanyuksel M, Petri WA, Jr. Laboratory diagnosis of amebiasis. Clin Microbiol Rev 2003;16:713-29.

24. Chen MJ, Lin CY, Wu YT, et al. Effects of extreme precipitation to the distribution of infectious diseases in Taiwan, 1994-2008. PLoS ONE 2012;7:e34651.

25. Centers for Disease Control DoH, Taiwan. Notifiable Infectious Diseases Statistics System. Secondary Notifiable Infectious Diseases Statistics System. http://nidss.cdc.gov.tw/SingleDisease. aspx pt $=s \& D c=2 \& D t=1 \&$ disease $=006 \& d=3 \& s=$ determined cnt\& $\mathrm{i}=$ all\&RK $=Y$

26. Hung CC, Chang SY, Ji DD. Entamoeba histolytica infection in men who have sex with men. Lancet Infect Dis 2012;12:729-36.

27. Kouadio IK, Koffi AK, Attoh-Toure H, et al. Outbreak of measles and rubella in refugee transit camps. Epidemiol Infect 2009;137:1593-601.

28. Bich TH, Quang LN, Ha le TT, et al. Impacts of flood on health: epidemiologic evidence from Hanoi, Vietnam. Glob Health Action 2011;4:6356.

29. Ding G, Zhang Y, Gao L, et al. Quantitative analysis of burden of infectious diarrhoea associated with floods in northwest of Anhui province, China: a mixed method evaluation. PLOS ONE 2013;8: e65112. 